\title{
Phenotypic profile of Rh blood group systems among females of child-bearing age in Pakistan
}

\begin{abstract}
Objective: To determine the distribution of major Rh antigens and its phenotype in women of child bearing age in Northern Pakistan.
\end{abstract}

Materials and method: The study was conducted in the Armed Forces Institute of Transfusion (AFIT), Rawalpindi in year 2016.A total of 850 female healthy donors of childbearing age from northern areas of Pakistan between 18 to 45 years were included in the study. Forward and reverse $\mathrm{ABO}$ grouping was performed by conventional tube method. Rh phenotyping (for rest of the major antigens of Rh system i.e. C, c, E and e) was done using Bio-Rad gel card.

Results: The phenotypic frequencies of Rh blood groups in the studied population were D-94.94\%, C-87.53\%, E-21.41\%, c-61.18\% and e-98.59\%. Thus 'e' was the most common and E was the least common of all the Rh types. Phenotypically DCCee group was the most common phenotype.

Conclusion: Determination of population based frequency data of $\mathrm{Rh}$ antigens and phenotypes can play a major role in predicting and managing haemolytic disease of the fetus and newborn (HDFN) and preventing alloimmunization and avoiding adverse events in multi-transfusion cases.

Keywords: Rh blood group, Rh phenotypes, Pakistan

\author{
Volume 6 Issue I - 2018
}

\author{
Rafia Mahmood,' Maqbool Alam, ${ }^{2}$ Chaudhry \\ Altaf,' Asad Mehmood Abbasi, ${ }^{2}$ Hamid Saeed \\ Malik' \\ 'Armed Forces Institute of Pathology, Pakistan \\ ${ }^{2}$ Armed Forces Institute of Transfusion, Pakistan
}

Correspondence: Rafia Mahmood, Department of Haematology, Armed Forces Institute of Pathology, CMH Road, Rawalpindi, Pakistan, Fax 925।4I02783, Tel 923365।82270, Email rafiamahmood@hotmail.com

Received: January 12, 2018 | Published: February 09, 2018

\section{Introduction}

The Rh blood group system discovered in 1939 is only second in importance to the ABO system in terms of transfusion. ${ }^{1}$ It is a highly complex blood group system with more than fifty different antigens. ${ }^{2}$ However, most clinical transfusion issues are associated with the five principal antigens $\mathrm{D}, \mathrm{C}, \mathrm{c}, \mathrm{E}$ and $\mathrm{e}$. Rh antigens are non-glycosylated proteins in the RBC membrane. ${ }^{3}$ Two closely linked genes on chromosome 1 control the expression of $\mathrm{Rh}$; one gene $\mathrm{RhD}$ codes for the presence of $\mathrm{RhD}$, and a second gene codes for the expression of CcEe antigens. ${ }^{4}$ The $\mathrm{Rh}$ antigens are thought to play a role in maintaining the integrity of the RBC membrane. They may also be involved in transport of ammonium across the RBC membrane. ${ }^{5}$

Red blood cell stimulation through transfusion or pregnancy leads to antibody production. ${ }^{4}$ Most $\mathrm{Rh}$ antibodies are $\mathrm{IgG}$ immunoglobulin and can cross the placenta. ${ }^{6} \mathrm{Rh}$ antibodies have been implicated as a clinically significant cause of hemolytic disease of the fetus and newborn (HDFN) and hemolytic transfusion reactions (HTR), usually delayed transfusion reactions. ${ }^{7} \mathrm{Rh}$ antibodies do not bind complement and $\mathrm{Rh}$ mediated hemolytic transfusion reactions usually result in extra vascular hemolysis. ${ }^{8}$ HDFN occurs due to the maternal $\mathrm{IgG}$ antibody that crosses the placenta. This antibody binds to the fetal antigen-positive RBCs, thus leading to their hemolysis. ${ }^{9}$ Of all the $\mathrm{RBC}$ antigens, $\mathrm{D}$ is the most immunogenic and responsible for the most severe cases of HDFN. ${ }^{10}$ The introduction of RhIG ( $\mathrm{Rh}$ immune globulin) has reduced the incidence of Rh HDFN. Anti-c is the second most common cause followed by anti-E. ${ }^{11}$

Blood group distributions are different and distinctive for population groups, and can show noticeable differences in geographic prevalence around the world. ${ }^{12}$ The present study was designed with an aim to see the prevalence and distribution of the Rh antigens in our part of the country as so far there is lack of data on the frequency of $\mathrm{Rh}$ phenotypes in our region. Knowledge of the distribution of $\mathrm{Rh}$ antigens in our population can be useful for blood banks to maintain their inventory, to find antigen negative blood for alloimmunized patients, to calculate the number of blood units to be cross-matched to find a compatible unit and for the preparation of indigenous cell panels. It is also important as it helps to predict HDFN. This study provides a database to blood banks and transfusion centers for searching antigen negative blood for alloimmunized patients and for the preparation of indigenous cell panels. ${ }^{13}$

\section{Materials and methods}

\section{Subjects}

A total of 850 healthy females from northern areas of Pakistan were randomly selected for red cell Rh phenotyping. They belonged to different ethnic groups including Pathans, Punjabis, Sindhi, Balochis and people from Gilgit Baltistan. Patients were between the ages of 18-45years. Blood samples were collected from females who came for routine blood grouping, females coming to gynecology and obstetrics outpatient department and indoor patients admitted in gynecology and obstetrics ward. Females with no previous history of any transfusion were included only. All subjects were elaborately apprised about the study and written informed consent was obtained.

\section{Blood grouping and Rh phenotyping}

A $5 \mathrm{ml}$ sample of blood was drawn from antecubital vein and $2 \mathrm{ml}$ transferred immediately to a tube containing EDTA and $3 \mathrm{ml}$ collected in plain tube. Forward and reverse ABO grouping was performed by 
conventional tube method. Rh D typing was done by tube method using monoclonal/polyclonal anti-D. Rh phenotyping (for rest of the major antigens of Rh system i.e. C, c, E and e) was done using BioRad gel card according to manufacturer instructions.

\section{Data analysis}

All the collected data were entered in statistical package for social sciences (SPSS) version 20. The analyzed variables included D, C, $\mathrm{c}, \mathrm{E}$ and $\mathrm{e}$ antigen and allele frequencies were calculated from these. Phenotype were observed, noted and expressed as percentages and most probable genotypes were determined from gene frequency estimates. Data was entered and analyzed using SPSS version 20

\section{Ethical approval}

This study was approved by the Ethical Review Committee of Armed Forces Institute of Transfusion, Rawalpindi. Informed written consent was taken from the patients.

\section{Results}

A total of 850 patients were included in this study. Mean age of the patients was 28.16 \pm 8.30 years (ranging from 18-45years). ABO grouping in this study showed that the most common blood group was B seen in $285(33.53 \%)$, followed closely by blood group $\mathrm{O}$ in $252(29.65 \%)$ of the sample population. Blood group A was seen in $230(27.06 \%)$ of the females with blood group $\mathrm{AB}$ in $83(9.76 \%)$ being the least common. In the Rh blood group, 807 females representing $94.94 \%$ of the sample population were found to be $\mathrm{RhD}$ positive while $43(5.06 \%)$ of the females were $\mathrm{RhD}$ negative. Weak D was not detected in any of the females.

Of the five antigens that were phenotyped, the e antigen was found to have the highest frequency $(98.59 \%)$, followed by $\mathrm{D}(94.94 \%)$ and $\mathrm{C}(87.53 \%)$ antigens as shown in Table 1 . The lowest prevalence was observed for the $\mathrm{E}$ antigen $(21.41 \%)$. The most common phenotype was DCCee(38.82\%), followed by DCcee(32.71) and DCcEe(14.24\%). The least common phenotypes were dccee(2.71\%), Dccee(2.6\%), dCcee $(1.76 \%)$, DccEE(1.4\%), dccE( $0.6 \%)$. No case of phenotype $\mathrm{dCcEe}$ and dCCEE was detected (Table 2). We also compared the frequency of these $\mathrm{Rh}$ antigens $(\mathrm{C}, \mathrm{c}, \mathrm{E}, \mathrm{e})$ in $\mathrm{RhD}$ positive and $\mathrm{RhD}$ negative females in the study population. In RhD positive females, antigen e $(98.51 \%)$ followed by C $(90.33 \%)$ was most frequent while in $\mathrm{RhD}$ negative females, the most frequent antigens were e $(97.67 \%)$ and c $(97.67 \%)$.

Table I Frequency of red cell Rh antigens in the study population

\begin{tabular}{lll}
\hline Red cell antigen & No of persons $(\mathbf{N}=850)$ & $\%$ \\
\hline D & 807 & 94.94 \\
d & 43 & 5.06 \\
C & 744 & 87.53 \\
C & 520 & 61.18 \\
E & 182 & 21.41 \\
e & 838 & 98.59 \\
\hline
\end{tabular}

Table 2 Reaction pattern with antisera, phenotype and probable genotype frequencies in the study population

\begin{tabular}{|c|c|c|c|c|c|c|c|}
\hline \multicolumn{5}{|c|}{ Results with anti-sera } & \multirow{2}{*}{ Phenotype } & \multicolumn{2}{|c|}{ Frequency } \\
\hline D & C & $\mathbf{E}$ & c & e & & $N=850$ & $\%$ \\
\hline+ & + & - & - & + & $\mathrm{DCe}$ & 330 & 38.82 \\
\hline+ & + & - & + & + & DCce & 278 & 32.71 \\
\hline+ & + & + & + & + & $\mathrm{DCcEe}$ & 121 & 14.24 \\
\hline+ & - & + & + & - & $\mathrm{DcE}$ & 12 & 1.4 \\
\hline+ & - & - & + & + & Dce & 22 & 2.6 \\
\hline+ & - & + & + & + & DcEe & 44 & 5.18 \\
\hline- & - & - & + & + & $\mathrm{Ce}$ & 23 & 2.71 \\
\hline- & + & - & + & + & Cce & 15 & 1.76 \\
\hline- & - & + & + & - & $\mathrm{cE}$ & 5 & 0.6 \\
\hline
\end{tabular}

\section{Discussion}

Among the blood group systems, after the $\mathrm{ABO}, \mathrm{Rh}$ is the second most important blood group system. ${ }^{11} \mathrm{ABO}$ antibodies are typically found in individuals who lack the corresponding antigen but in the $\mathrm{Rh}$ system, it is only after exposure to foreign red blood cell antigens that $\mathrm{Rh}$ antibodies are formed. ${ }^{2}$ The exposure to red cell antigens may be through transfusions or pregnancies. ${ }^{12}$ Once alloantibodies against foreign antigens are made, they can produce significant hemolytic disease of the fetus and newborn and hemolytic transfusion reactions. ${ }^{6}$ Karim et al. ${ }^{9}$ in a study conducted in Pakistan has reported the risk of sensitization with D antigen in D negative women to be as high as $2.2 \%{ }^{9}$

There are very few studies from Pakistan on Rh phenotype frequencies. Armed Forces Institute of Transfusion is a big institute in north of the country. It caters to a large number of people from all over the country from very different ethnic backgrounds, including patients from tribal areas and Peshawar which are Pathan in origin and patients from Gilgit, Baltistan and Abbottabad and from north of Punjab. This study helps us to determine the Rh antigen prevalence in our population, thus providing a database to blood banks and transfusion centers for predicting the alloantibodies formed in patients receiving transfusions, predicting HDFN, searching antigen negative blood for alloimmunized patients and for the preparation of in-house panel cells.

$\mathrm{ABO}$ grouping in this study showed that $\mathrm{B}(33.53 \%)$ was the most common blood group, followed by $\mathrm{O}(29.65 \%)$ while $\mathrm{AB}(9.76 \%)$ was the least common. These findings are in accordance with an Indian study by Garg et al. ${ }^{14}$ that has reported B to be the most common blood group in the Indian population and $\mathrm{AB}$ to be the least common. However, blood group $\mathrm{O}$ has been reported to be the most common in population from southern Pakistan in a local study by Karim et al. ${ }^{15}$

Our result of $94.94 \% \mathrm{RhD}$ positive persons is in agreement with a study by Sarkar et al. ${ }^{16}(92.25 \%)$ and Das et al. ${ }^{17}(94.53 \%)$. However, Fisher et al. ${ }^{18}$ has reported a frequency of $83-85 \%$ in Europeans and Americans and a frequency of $99 \%$ in the Chinese population. Of the Rh antigens, the e antigen (98.59\%) had the highest frequency, followed by $\mathrm{C}$ antigen $(87.53 \%)$. Our results match with those of another local study by Karim et al. ${ }^{15}$ who has reported e 
antigen- $99 \%$ and $\mathrm{C}$ antigen-87\%. Frequency of e antigen-97.9\% and $\mathrm{C}$ antigen- $75.9 \%$ has been reported in the Iranian population by
Keramati et al. ${ }^{19}$ Table 3 shows the frequency of the Rh antigens as reported in different studies.

Table 3 Comparison of frequency of Rh antigens in different populations in the world

\begin{tabular}{lllll}
\hline Antigen & Our study Pakistan \% & Karim et al. ${ }^{15}$ Pakistan & Keramati et al. ${ }^{19}$ Iran & Bogui et al. ${ }^{20}$ Africa \\
\hline D & 94.94 & 97 & 90.2 & 92.93 \\
C & 87.53 & 87 & 75.9 & 21.97 \\
C & 61.18 & 57 & 73.9 & 99.85 \\
E & 21.41 & 19 & 29.5 & 13.82 \\
e & 98.59 & 99 & 97.9 & 99.85 \\
\hline
\end{tabular}

The antigen frequencies of other $\mathrm{Rh}$ antigens $(\mathrm{C}, \mathrm{c}, \mathrm{E}, \mathrm{e})$ in $\mathrm{D}$ positive individuals and their frequencies in $\mathrm{Rh} \mathrm{D}$ negative individuals are compared with those of the Indian population ${ }^{16}$ in Figure $1 \&$ Figure 2 respectively. The most common Rh phenotype in our population is DCCee (38.82\%), followed by Dccee (32.71\%). These findings are consistent with those reported by Sarkar et al. ${ }^{16}$
He has reported the frequency of DCCee as $35.2 \%$, the most frequent in the Indian population and Dccee as $30.7 \%$, second most frequent in their population. However, the frequency of DCCee is $17.6 \%$ in Whites and $2.9 \%$ in Africans, while the frequency of Dccee is $31.1 \%$ in Whites and $8.8 \%$ in the African population ${ }^{11-13}$ as shown in Table 4.

Table 4 Comparison of Rh phenotype frequencies in different populations in the world

\begin{tabular}{|c|c|c|c|c|c|}
\hline Phenotypes & Our Study Pakistan \% & Karim et al. ${ }^{15}$ Pakistan & Sarkar et al. ${ }^{16}$ India & African blacks II-I3\% & Whites II-13\% \\
\hline $\mathrm{DCe}$ & 38.82 & 41 & 35.2 & 2.9 & 17.6 \\
\hline Dce & 32.71 & 34 & 30.7 & 8.8 & 31.1 \\
\hline DCcEe & 14.24 & 10 & 8.1 & 3.7 & 11.8 \\
\hline DcE & 1.4 & 1 & 0.7 & 1.3 & 2 \\
\hline Dce & 2.6 & 3 & 2.2 & 22.9 & 3 \\
\hline DcEe & 5.18 & 8 & 5.9 & 5.7 & 10.4 \\
\hline $\mathrm{Ce}$ & 2.71 & 1 & 0.3 & 7 & 15 \\
\hline Cce & 1.76 & I & 2.5 & I & I \\
\hline $\mathrm{cE}$ & 0.6 & I & Rare & Rare & I \\
\hline
\end{tabular}

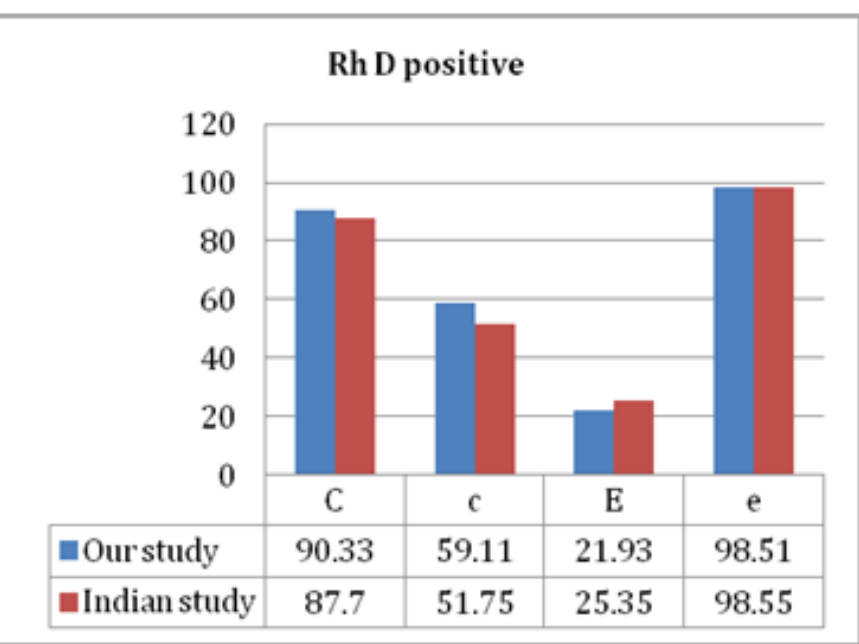

Figure I Comparison of frequency of Rh antigens in Rh D positive.

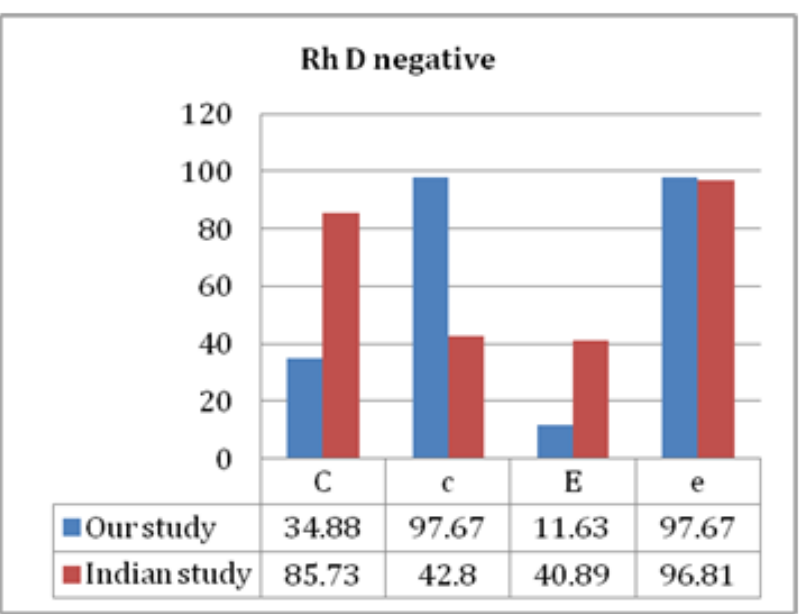

Figure 2 The comparison of frequency of Rh antigens in Rh D negative individuals in our study and an Indian study. ${ }^{16}$ 


\section{Conclusion}

This study has documented Rh antigen frequency in population of Northern Pakistan. We have compared our data with Iranians, Africans and Indian population and found that the frequencies in our population resemble those in Indians and Iranians. The data are useful not only for creating a donor data base and finding antigen negative compatible blood for alloimmunized patients but also for the preparation of indigenous panel cells. We have performed only serological investigations and as the gene frequency of Rh antigens is not clearly known in our population, so further studies including molecular investigations are required on this subject using large sample size to establish the genetic make-up of $\mathrm{Rh}$ system in our population.

\section{Acknowledgements}

We are grateful for the technical support provided by Muhammad Yaqoob.

\section{Conflict of interest}

No potential conflicts of interest relevant to this article were reported.

\section{References}

1. Karl Landsteiner, Alexander S Wiener. An agglutinable factor in human blood recognized by immune sera for rhesus blood. Experimental Biology and Medicine. 1940;43(1):223.

2. Agre P, Cartron JP. Molecular biology of the Rh antigens. Blood. 1991;78(3):551-563.

3. Anstee DJ, Tanner MJ. Biochemical aspects of the blood group Rh (rhesus) antigens. Baillieres Clin Haematol. 1993;6(2):401-422.

4. Jeffrey McCullough. Chapter 57: Transfusion msedicine. In: Robert I Handin, et al. editors. Blood: Principles and Practice of Hematology. 1st ed. USA: Lippincott Williams \& Wilkink; 2003. 2021 p.

5. Avent ND, Reid ME. The Rh blood group system: a review. Blood. 2000;95(2):375-387.

6. Calhoun L, Petz LD. Erythrocyte antigens. In: Bentler E, et al. editors. Williums Haematology. 6th ed. Health Professions Division, New York, USA: McGraw Hill, Inc; 2001
7. Flegel WA. The genetics of the Rhesus blood group system. Blood Transfus. 2007;5(2):50-57.

8. Reid ME, Lomas-Francis C. The Blood Group Antigen Facts book. 2nd ed. USA: Academic Press; 2004.

9. Karim F, Moiz B, Kamran N. Risk of maternal alloimmunization in Southern Pakistan-a study in a cohort of 1000 pregnant women. Transfus Apher Sci. 2015;52(1):99-102.

10. Thakral B, Saluja K, Sharma RR, et al. Phenotype frequencies of blood group systems (Rh, Kell, Kidd, Duffy, MNS, P, Lewis, and Lutheran) in north Indian blood donors. Transfus Apher Sci. 2010;43(1):17-22.

11. Brecher ME. Technical Manual. 15th ed. USA: American Association of Blood Banks; 2005. e223, e240, e315-e334 p.

12. Daniels G. Human Blood Groups. 2nd ed. Cambridge, Massachusetts, USA: Blackwell Science; 2002.

13. Harmening DM. Modern Blood Banking and Transfusion Practices. 5th ed. USA: Davis Company; 2005. p. 134-147.

14. Garg P, Upadhyay S, Chufal SS, et al. Prevalance of ABO and Rhesus blood groups in blood donors: a study from a tertiary care teaching hospital of Kumaon region of Uttarakhand. J Clin Diagn Res. 2014;8(12):FC16-19.

15. Karim F, Moiz B, Muhammad FJ, et al. Rhesus and kell phenotyping of voluntary blood donors: foundation of a donor data bank. J Coll Physicians Surg Pak. 2015;25(10):757760.

16. Sarkar RS, Philip J, Mallhi RS, et al. Proportion of Rh phenotypes in voluntary blood donors. Med J Armed Forces India. 2013;69(4):330 334.

17. Das PK, Nair SC, Harris VK, et al. Distribution of ABO and Rh-D blood groups among blood donors in a tertiary care centres in South India. Trop Doct. 2001;31(1):47-48.

18. Fisher RA. The fitting of gene frequencies to data on Rhesus reactions Ann Eugen. 1946;13(Pt 2):150-155.

19. Keramati MR, Shakibaei H, Kheiyyami MI, et al. Blood group antigens frequencies in the northeast of Iran. Transfus Apher Sci. 2011;45(2):133136.

20. Bogui LS, Dembele B, Sekongo Y, et al. Phenotypic profile of Rh and Kell blood group systems among blood donors in Cote d'Ivoire, West Africa. Journal of Blood Transfusion. 2014;309817:1-4. 